УДК 911.6:912.43:553.3/.9(571.56)

РАЙОНИРОВАНИЕ ТЕРРИТОРИИ ЗОНЫ ТРАНСПОРТНОГО КОРИДОРА
СКОВОРОДИНО - ТИКСИ ПО СОЧЕТАНИЮ МИНЕРАЛЬНЫХ РЕСУРСОВ

Ткаченко Г.Г.

ФГБУН «Тихоокеанский институт географии» ДВО РАН, Владивосток, e-mail: tkatchenko-gri@mail.ru

\begin{abstract}
Для территории зоны транспортного коридора Сковородино - Тикси (ЗТКСТ) проведено природно-ресурсное районирование на основе рассмотрения месторождений твердых минеральных ресурсов. При этом территория рассматривается на уровне муниципальных районов (учитываются административные границы районов) так как результаты районирования должны быть учтены в программах и схемах социально-экономического развития муниципальных территорий Республики Саха (Якутия) и Амурской области. Прежде всего, дана краткая экономико-географическая характеристика, а затем и общая характеристика месторождений минеральных ресурсов ЗТКСТ. Выявлены географические и структурные особенности распространения месторождений минерального сырья. Определено, что минерально-сырьевая база ЗТКСТ имеет ярко выраженный характер «окраинных территорий», когда в структуре месторождений преобладают месторождения высоколиквидных видов ресурсов. Все виды минеральных ресурсов сгруппированы в 8 основных ресурсных групп. Предложен следующий порядок минерально-ресурсного районирования. На первом этапе были выделено два типа, а в каждом из них три подтипа муниципальных районов по преобладанию на их территории месторождений основных ресурсных групп. Дана характеристика особенностей минерально-ресурсного потенциала по каждому типу районов. На втором этапе, с учетом предложенной типологии и географического положения, муниципальные образования распределены в 6 минерально-ресурсных районов, каждому из которых присвоено название, отражающее также и его географическое положение. В характеристике минерально-ресурсных районов показан уникальный характер географического положения и сочетания минеральных ресурсов, выделены общие черты и различия, а вместе с тем слабые и сильные стороны минерально-сырьевой базы. Отмечается, что минерально-ресурсные преимущества одних районов над другими означают их более ускоренное социально-экономическое развитие.
\end{abstract}

Ключевые слова: минеральные ресурсы, месторождения, транспортный коридор, районирование территории, территориальные сочетания, природно-ресурсный район

\title{
ZONING OF THE TERRITORY OF THE TRANSPORT CORRIDOR SKOVORODINO - TIKSI BY THE COMBINATION OF MINERAL RESOURCES
}

Tkachenko G.G.

Pacific Institute of Geography Far Eastern Branch Russian Academy of Sciences, Vladivostok,e-mail: tkatchenko-gri@mail.ru

For the territory of the zone of the transport corridor Skovorodino-Tiksi (ZTCST), natural resource zoning was carried out on the basis of consideration of deposits of solid mineral resources. The territory is considered at the level of municipal districts (administrative boundaries of districts are taken into account) since the results of zoning should be taken into account in programs and schemes of socio-economic development of municipal territories of the Republic of Sakha (Yakutia) and the Amur region. First of all, the brief socio-economic description, and then and General characteristics of deposits of mineral resources of ZTCST is done. Geographical and structural features of mineral deposits distribution are revealed. It is determined that the mineral resource base of ZTCST has a pronounced character of «periphery areas», when the structure of deposits is dominated by deposits of highly liquid types of resources. All types of mineral resources are grouped into 8 main resource groups. The following order of mineral resource zoning is proposed. At the first stage, two types were allocated, and in each three subtypes of municipal districts on the predominance of deposits of the main resource groups on their territory. The characteristic features of mineral resource potential for each type of areas. In the second stage, taking into account the proposed typology and geographical location, the municipalities are divided into 6 mineral resource areas, each of which is assigned a name that also reflects its geographical location. The characteristic of mineral resource areas shows the unique nature of the geographical location and combination of mineral resources, identified common features and differences, and at the same time the strengths and weaknesses of the mineral resource base. It is noted that the mineral and resource advantages of some areas over others mean their more rapid socio-economic development.

Keywords: mineral resources, deposits, transport corridor, zoning, territorial combinations, natural resource area

Зона транспортного коридора Сковородино - Тикси (ЗТКСТ) включает в себя территорию 16 муниципальных образований двух субъектов Дальневосточного федерального округа (ДФО) России. Это два района Амурской области - Сковородинский и Тындинский и 13 улусов и 1 городской округ Республики Саха (Якутия) (табл. 1). По территории некоторых из них пролегают железнодорожные, автомобильные или морские пути, которые могут связать Сковородино, а через пограничный переход и китайскую территорию с северным портом Тикси. Перспективный транспортный коридор Сковородино - Тикси может стать новым вектором как в развитии транс- 
портной инфраструктуры ДФО, так и еще одним направлением в структуре Нового Шелкового пути. Реализация транспортных перевозок по этому маршруту позволит включить в зону активных экономических интересов обширные слабо развитые в социально-экономическом отношении, но богатые разнообразным природно-ресурсным потенциалом континентальные территории Якутии [1].

Цель исследования: выделить природно-ресурсные районы, показав для каждого уникальный характер географического положения и сочетания минеральных ресурсов.

\section{Материалы и методы исследования}

В географических исследованиях традиционно подходы и методы изучения пространственной дифференциации природных ресурсов сложились в виде тех или иных их сочетаний в пределах каких-либо территорий или регионов с помощью методов зонирования или районирования. При этом производится выделение как групп однородных природных ресурсов (черных или цветных металлов, угольных ресурсов, строительного сырья, земельных, лесных и т.п.), так и их сочетаний [4-6]. Для практического применения схем районирования, в частности в программах регионального развития и управления, районирование территории целесообразно осуществлять в рамках муниципальных границ районов субъектов РФ. В работе использованы статистические данные по объектам учета государственного кадастра месторождений Федерального агентства по недропользованию Роснедра [2].

\section{Результаты исследования и их обсуждение}

Площадь территории ЗТКСТ составляет 1049,7 тыс км², или $15,1 \%$ от площади ДФО. По состоянию на 2018 г. здесь проживает 673,6 тыс. человек, или 8,2\% населения ДФО. Плотность населения составляет 0,64 чел на км², что ниже аналогичного показателя по ДФО в 2 раза. Транспортная инфраструктура ЗТКСТ представлена пятью основными видами транспорта, которые имеют неравнозначное значение для социально-экономического развития: речной, автомобильный, авиационный, железнодорожный и трубопроводный. Численность месторождений твердого минерального сырья составляет 1317 или 14\% от численности месторождений ДФО. Плотность месторождений составляет 1,25 на 1000 км².
Геологическая изученность данной территории даже в сравнении с другими территориями ДФО незначительна за исключением южных районов. Распределение численности месторождений по административным районам показано в табл. 1. Среди них наибольшее число месторождений сосредоточено в Алданском (треть всех месторождений ЗТКСТ), Тындинском, Нерюнгринском и Сковородинском. При этом плотность месторождений наивысшая в ГО Якутск. Если не брать во внимание сравнительно небольшой по территории ГО, наибольшая плотность месторождений характерна для следующих районов: Сковородинского, Тындинского, Алданского и Нерюнгринского. Наименьшая плотность месторпождений в Жиганском, Горном, Чураппчинском и Булунском районах (табл. 1).

Всего в ЗТКСТ выявлены месторождения 58 видов минерального сырья (кроме попутных видов). Наибольшее количество видов из них представлено в Алданском и Тындинском районах, а также в Нерюнгринском и Сковородинском районах. В остальных районах большого разнообразия минеральных ресурсов не наблюдается, а представлены лишь 3-9 видов минерального сырья (табл. 1). С точки зрения географического распределения численности месторождений между субъектами ДФО заметное преимущество закономерно (исходя из площади территории) имеет Республика Саха, на которую приходится 68,5\% от численности месторождений ЗТКСТ. Минерально-сырьевая база ЗТКСТ имеет ярко выраженный характер «окраинных территорий», когда в видовой структуре преобладают месторождения высоколиквидных ресурсов, в данном случае - золота, на которое приходится более $62 \%$ от численности месторождений минерального сырья ЗТКСТ. Численность месторождений по другим видам ресурсов значительно ниже. На 10 основных видов ресурсов приходится почти $88 \%$ от численности всех месторождений.

Полезные ископаемые распределены по восьми основным ресурсным группам (табл. 2). Наибольшее количество видов представлено в группе строительных материалов - 31 и цветных металлов -8 . На группу благородных металлов приходится $64,1 \%$, а на группу строительных материалов - 19,3\% всех месторождений. На другие группы приходится всего 16,6\% от численнсти месторождений. Очевидно, что минерально-ресурсную специфику районообразования в ЗТКСТ определяют 
минеральные ресурсы первых двух групп. Географические различия распределения месторождений по субъектам ДФО также представлены в табл. 1. Важной особенностью для районов, относящихся к Амурской области, является еще более высокая доля месторождений группы благородных металлов - 82,7\% в сравнении с аналогичным показателем в целом по ЗТКСТ.

Исходя из результатов анализа географической и видовой структуры месторождений по административным территориям
ЗТКСТ, на первом этапе районирования были выделены типы муниципальных районов по преобладанию на их территории численности месторождений основных ресурсных групп. Выделено два типа таких районов, каждый из которых имеет по три подтипа (рисунок). Выделение подтипов связано с необходимостью более детального рассмотрения особенностей сочетания минеральных ресурсов, их сходства и различия на уровне муниципальных районов.

Распределение месторождений минерального сырья по районам ЗТКСТ

\begin{tabular}{|c|c|c|c|c|c|c|c|}
\hline \multirow[t]{2}{*}{ № } & \multirow{2}{*}{ Районы } & \multirow{2}{*}{$\begin{array}{c}\text { Площадь } \\
\text { территории, } \\
\text { тыс. км² }\end{array}$} & \multirow{2}{*}{$\begin{array}{c}\text { Население } \\
\text { тыс. чел. }\end{array}$} & \multicolumn{3}{|c|}{ Месторождения } & \multirow{2}{*}{\begin{tabular}{|c|} 
Кол-во \\
видов \\
ресурсов
\end{tabular}} \\
\hline & & & & $\begin{array}{c}\begin{array}{c}\text { Кол-во, } \\
\text { ед. }\end{array} \\
\end{array}$ & $\begin{array}{c}\text { Доля от } \\
\text { ЗТКСТ, \% }\end{array}$ & $\begin{array}{l}\text { Плотность } \\
\text { на } 1000 \text { км }^{2}\end{array}$ & \\
\hline & Республика Саха & 945,9 & 633,1 & 902 & 68,5 & 0,95 & 42 \\
\hline 1 & Булунский & 235,1 & 8,3 & 29 & 2,2 & 0,12 & 5 \\
\hline 2 & Жиганский & 140,2 & 4.2 & 17 & 1,3 & 0.1 & 7 \\
\hline 3 & Вилюйский & 55,2 & 25 & 12 & 0,9 & 0,24 & 3 \\
\hline 4 & Кобяйский & 107,8 & 12,4 & 51 & 3,9 & 0,47 & 9 \\
\hline 5 & Горный & 45,6 & 12 & 4 & 0,3 & 0,1 & 2 \\
\hline 6 & Намский & 11,9 & 24,6 & 4 & 0,3 & 0,34 & 3 \\
\hline 7 & Усть-Алданский & 18,3 & 20,8 & 4 & 0,3 & 0,22 & 4 \\
\hline 8 & Хангаласский & 24,7 & 32,6 & 32 & 2,5 & 1,3 & 6 \\
\hline 9 & ГО Якутск & 3,6 & 311 & 19 & 1,4 & 8,1 & 4 \\
\hline 10 & Мегино-Кангаласский & 11,7 & 31 & 14 & 1,1 & 1,2 & 2 \\
\hline 11 & Чурапчинский & 12,6 & 21,1 & 7 & 0,5 & 0.1 & 5 \\
\hline 12 & Амгинский & 29,4 & 16,7 & 9 & 0.7 & 0,27 & 4 \\
\hline 13 & Алданский & 156,8 & 39,4 & 443 & 33,6 & 2,8 & 21 \\
\hline 14 & Нерюнгринский & 93 & 74 & 257 & 19,5 & 2,76 & 20 \\
\hline & Амурская обл. & 103,8 & 40,5 & 415 & 31,5 & 4 & 30 \\
\hline 15 & Тындинский & 83,3 & 13,5 & 299 & 22,7 & 3,6 & 21 \\
\hline 16 & Сковородинский & 20.5 & 27 & 116 & 8,8 & 5,7 & 16 \\
\hline & ВСЕГО & 1049,7 & 673,6 & 1317 & 100 & 1,25 & 58 \\
\hline
\end{tabular}

Пр и м еч ан и е . [Сост. по: 2, 3].

Таблица 2

Видовая структура месторождений твердого минерального сырья

\begin{tabular}{|l|c|c|c|}
\hline \multicolumn{1}{|c|}{ Группа полезных ископаемых } & $\begin{array}{c}\text { Численность месторождений } \\
\text { (Якутия + Амурская обл.) }\end{array}$ & $\begin{array}{c}\text { Доля от числа ме- } \\
\text { сторождений, } \%\end{array}$ & $\begin{array}{c}\text { Кол-во видов } \\
\text { ресурсов }\end{array}$ \\
\hline Поделочные и ювелирные камни & $12(12+0)$ & 0,9 & 4 \\
\hline Редкие и редкозем., уран & $38(31+7)$ & 2,9 & 3 \\
\hline Цветные металлы & $30(9+21)$ & 2,3 & 3 \\
\hline Благородные металлы & $844(505+343)$ & 64,1 & 1 \\
\hline Черные металлы & $16(13+3)$ & 1,2 & 3 \\
\hline Топливно-энергетические & $79(78+1)$ & 6 & 4 \\
\hline Неметаллы & $44(42+2)$ & 3,3 & 31 \\
\hline Строительные материалы & $254(218+36)$ & 19,3 & 58 \\
\hline ВСЕГО & $1317(902+415)$ & 100 & \\
\hline
\end{tabular}

Пр и ме ч ан ие. [Сост. по: 2]. 


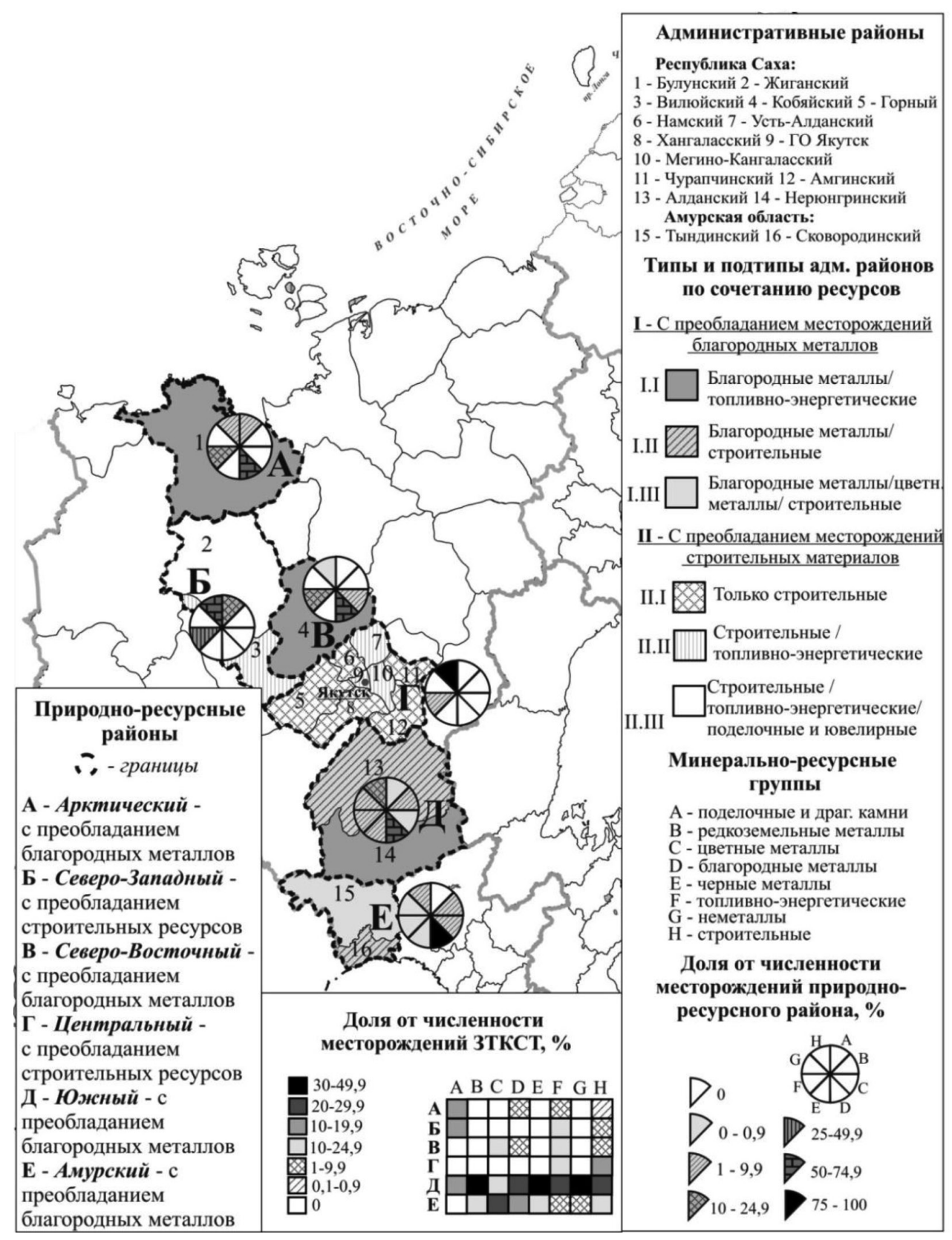

Районирование территории ЗТКСТ по сочетанию месторождений минеральных ресурсов [Сост. по: 2]

Учитывая то, что месторождения строительных материалов представлены во всех районах, они также присутствуют во всех выделенных нами типах районов по сочетанию ресурсов. Для выделения специфики и главных различий каждого из типов районов и их подтипов в нх названии на первое место поставлена ресурсная группа преобладающих по численности месторождений. На второе место - следующая по численности месторождений ресурсная группа. В том случае, если второй по численности месторождений являлась группа строительных материалов, она отодвигалась на третий план в пользу следующей за ней, но более точно отражающей специфику минерально-ресурсных сочетаний. Так, например, в подтипе I.III на второе место поставлена группа цветных металлов, хотя по численности месторождений она уступает группе строительных материалов. 
I-му типу соответствуют 6 муниципальных образований (рисунок). На данной территории сосредоточено $89,1 \%$ от численности месторождений ЗТКСТ. Данный тип районов является определяющим для минерально-ресурсного потенциала ЗТКСТ. Специфика подтипов в данном типе районов заключается в том, что каждый из них обладает абсолютным преимуществом (более $50 \%$ ) по численности месторождений одной или нескольких основных ресурсных групп: I.I - поделочных и драгоценных камней, черных металлов, топливно-энергетических ресурсов; I.II - редкоземельных металлов, неметаллического сырья; I.III цветных металлов (рисунок).

II-му типу соответствуют 10 муниципальных образований, расположенных в континентальной части Республики Саха. Bce муниципальные образования данного типа имеют малую численность месторождений. Таким образом, в целом данный тип районов является второстепенным для характеристики минерально-ресурсного потенциала ЗТКСТ.

На втором этапе районирования ЗТКСТ с учетом предложенной типологии и географического положения муниципальные образования распределены в 6 природно-ресурсных районов (ПРР) (табл. 3, рисунок). Каждому из них присвоено название, отражающее его географическое положение. При этом 4 района выделены на основе I типа и 2 района на основе II типа сочетания минеральных ресурсов. Далее дана краткая характеристика природно-ресурсных районов.

Арктический ПРР с преобладанием месторождений благородных металлов территориально совпадает с Булунским улусом Якутии и входит в арктическую зону России. Занимает второе место по площади территории среди ПРР ЗТКСТ. По численности месторождений делит последнее-предпоследнее место с Северо-западным ПРР. В видовой структуре месторождений преобладают месторождения благородных металлов (золото), составляя $69 \%$ от месторождений района и топливно-энергетических ресурсов (каменный и бурый уголь) - 17,2\%. По численности населения (8,3 тыс. чел.) данный ПРР занимает последнее место. Район в экономическом плане освоен слабо.

Северо-западный ПРР с преобладанием строительных ресурсов включает территорию Жиганского и Вилюйского улусов Якутии. Жиганский улус входит в расширенный состав арктической зоны России. По площади территории этот ПРР заниамает третье место. По численности месторождений делит последнее-предпоследнее места с Арктическим ПРР. В видовой структуре месторождений преобладают месторождения строительных материалов - 58,6\% (в основном песок и песчано-гравийный материал). На топливно-энергетические ресурсы (бурый уголь) приходится оклоло $30 \%$. Выявлены также немногочисленные месторождения алмазов и поделочного камня. По численности населения (16,6 тыс. чел.) занимает 4 место. В социально-экономическом отношении развит слабо.

Северо-восточный ПРР с преобладанием благородных металлов вкючает территорию только Кобяйского улуса Якутии. По площади территории занимает предпоследнее место среди ПРР, не многим уступая только Амурскому. В нем сосредоточено около $4 \%$ от численности месторождений ЗТКСТ. В видовой структуре месторождений преобладают месторождения благородных металлов (в основном серебра) - 69\%. Второй основной ресурсной группой является топливно-энергетическая (в основном месторождения природного газа и каменного угля) на которую приходится более $21 \%$ от месторождений района. Важным дополнением к ресурсныму сочетанию являются месторождения цветных металлов (свинец и олово). Район в социально-экономическом плане развит слабо.

Центральный ПРР с преобладанием строительных ресурсов самый представительный среди всех ПРР по количеству входящих в него муниципальных образований. В его состав входят следующие муниципальные образования Якутии: Горный, Намский, Усть-Алданский, Хангаласский, Мегино-Кангаласский, Чурапчинский, Амгинский улусы и ГО Якутск. Площадь его территории составляет $15 \%$ от ЗТКСТ. Здесь сосредоточено чуть более $7 \%$ от численности месторождений ЗТКСТ. В видовой структуре месторождений преобладают месторождения строительных материалов $95 \%$, среди которых наиболее многочисленны известняк, песок, и песчано-гравийный материал. Второй основной ресурсной группой является топливно-энергетическая (бурый уголь) на которую приходится оставшиеся $5 \%$ от месторождений района. В социально-экономическом плане район сравнительно развит. На его территории находится г. Якутск - социальный и экономический центр Якутии. Численность населения района составляет 470 тысяч человек или $70 \%$ от ЗТКСТ. 
Таблица 3

Характеристика природно-ресурсных районов по результатам районирования территории ЗТКСТ по сочетанию ресурсов твердого минерального сырья

\begin{tabular}{|l|c|c|c|c|}
\hline Название района & $\begin{array}{c}\text { Минерально- } \\
\text { ресурсный } \\
\text { тип района }\end{array}$ & $\begin{array}{c}\text { Площадь, } \\
\text { тыс км }{ }^{2} \\
\text { доля от 3ТКСТ }\end{array}$ & $\begin{array}{c}\text { Численность } \\
\text { месторождений / } \\
\text { доля от 3ТКСТ }\end{array}$ & $\begin{array}{c}\text { Основные ресурсные группы* } \\
\text { в структуре } \\
\text { месторождений,\% }\end{array}$ \\
\hline Арктический & I & $235,1 / 22,4$ & $29 / 2,2$ & $\mathrm{D}-69,1 ; \mathrm{F}-17,2$ \\
\hline Северо-западный & II & $195,4 / 18,6$ & $29 / 2,2$ & $\mathrm{H}-58,6 ; \mathrm{F}-29,6$ \\
\hline Северо-восточный & I & $107,8 / 10,3$ & $51 / 3,9$ & $\mathrm{D}-69,1 ; \mathrm{F}-21,6 ; \mathrm{C}-7,8$ \\
\hline Центральный & II & $157,8 / 15$ & $93 / 7,1$ & $\mathrm{H}-95 ; \mathrm{F}-5$ \\
\hline Южный & I & $249,8 / 23,8$ & $700 / 53,1$ & $\mathrm{D}-63,1 ; \mathrm{H}-15,6 ; \mathrm{F}-6,6$ \\
\hline Амурский & I & $103,8 / 9,9$ & $415 / 31,5$ & $\mathrm{D}-83,1 ; \mathrm{H}-8,7 ; \mathrm{C}-5,1$ \\
\hline
\end{tabular}

П р и м е ч а н и е . *Обозначение основных ресурсных групп дано на рисунке [Сост. по: 2].

Южный ПРР с преобладанием благородных металлов включает территорию Алданского и Нерюнгринского - самых южных улусов Якутии. Это самый большой по площади ПРР. Здесь сосредоточено 700 месторождений, или более $53 \%$ от всех месторождений ЗТКСТ. Плотность месторождений составля-

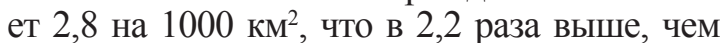
в среднем по ЗТКСТ. Из шести ПРР только в Южном присутствуют месторождения всех восьми основных ресурсных групп. По трем из них: редкоземельные, черные металлы и неметаллические ископаемые - доля района от ЗТКСТ превышает $75 \%$. По цветным металлам и топливно-энергетическим ресурсам превышает $50 \%$. В видовой структуре месторождений преобладают месторождения благородных металлов (в основном золото) $63 \%$ и строительных материалов - $15,6 \%$. Доля месторождений топливно-энергетических ресурсов составляет $6,6 \%$. Район экономически хорошо развит. Численность населения Южного ПРР составляет 113 тыс. человек, что является вторым показателем после Центрального ПРР.

Амурский ПРР с преобладанием благородных металлов включает территорию двух районов Амурской области - Тындинского и Сковородинского. Площадь данного ПРР чуть менее $10 \%$ от территории ЗТКСТ. В то же время здесь сосредоточено $31,5 \%$ от всех месторождений ЗТКСТ. Район является лидером по плотности месторожде-

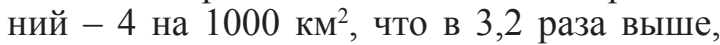
чем в среднем по территории ЗТКСТ. В видовой структуре преобладают месторождения благородных металлов (золото) - $83 \%$. На строительные материалы (в основном гранит, песок, гравий) приходится почти $9 \%$ месторождений. На цветные металлы (в основном молибден, вольфрам, титан) приходится около $5 \%$ месторождений. Район относительно хорошо развит. Население составляет 40,5 тыс. чел.

\section{Заключение}

Результаты исследований показывают общие черты и различия, а вместе с тем слабые и сильные стороны минеральноресурсных районов территории ЗТКСТ. Минерально-ресурсные сочетания как вид сравнительных преимуществ территории нового освоения проявляются по-разному и в различной мере могут быть востребованы в процессе их экономического развития. Чем больше востребованных месторождений и видов ресурсов имеет район, тем в большей степени вероятным становится его первоочередное освоение и привлечение инвестиций. Так как количество инвестиций в экономике, как правило, ограничено, минерально-ресурсные преимущества одних районов над другими означают их более ускоренное развитие, что особенно важно для местного населения.

Исследование выполнено при финансовой поддержке РФФИ в рамках научного проекта № 17-05-41044.

\section{Список литературы / References}

1. Тарасов П.И., Зырянов И.В., Хазин М.Л. Транспортный коридор через западную Якутию // Горный информационно-аналитический бюллетень (научно-технический журнал). 2018. № 6. C. 170-184. DOI: 10.25018/0236-14932018-6-0-170-184.

Tarasov P.I., Zyryanov I.V., Khazin M.L. Transport corridor through Western Yakutia // Gornyj informacionno-analiticheskij byulleten’ (nauchno-tekhnicheskij zhurnal). 2018. № 6. P. 170184 (in Russian).

2. Объекты учета государственного кадастра месторождений. Федеральное агентство по недропользованию Роснедра. РОСГЕОЛФОНД. [Электронный ресурс]. URL: http:// www.rfgf.ru/gkm/ (дата обращения: 10.06.2019).

Objects of accounting of the state cadaster of deposits. Federal'noe agentstvo po nedropol'zovaniyu Rosnedra. 
ROSGEOLFOND [Electronic resource]. URL: http://www.rfgf. $\mathrm{ru} / \mathrm{gkm} /$ (date of access: 10.06.2019) (in Russian).

3. Демографический ежегодник Республики Саха (Якутия): Статистический сборник. Я.: Федеральная служба гос. статистики, Территориальный орган Федеральной службы гос. статистики по Респ. Саха (Якутия), 2018. 262 с.

Demographic Yearbook of the Republic of Sakha (Yakutia) Statistical collection. Ya.: Federal'naya sluzhba gos. statistiki, Territorial'nyj organ Federal'noj sluzhby gos. statistiki po Resp. Saha (Yakutiya), 2018. 262 p. (in Russian).

4. Минц А.А. Экономическая оценка природных ресурсов. М.: Наука, 1972. 302 с.

Mintz A.A. Economic assessment of natural resources. M.: Nauka, 1972. 302 p. (in Russian).

5. Михайлов Ю.П. Территориальная организация природы и общества. Новосибирск: Наука, 2012. 351 с.
Mikhailov Yu.P. Territorial organization of nature and society. Novosibirsk: Nauka, 2012, 351 p. (in Russian).

6. Ткаченко Г.Г. Районирование российской части прибрежного региона Японского моря по сочетанию минеральных ресурсов // Геосистемы Северо-Восточной Азии: особенности их пространственно-временных структур, районирование территории и акватории: VII всероссийская научно-практическая конференция (г. Владивосток, 18-19 апреля). Владивосток: Тихоокеанский институт географии ДВО РАН, 2019. С. 484-491.

Tkachenko G.G. Zoning of the Russian part of the coastal region of the sea of Japan by the combination of mineral resources // Geosistemy Severo-Vostochnoj Azii: osobennosti ih prostranstvenno-vremennyh struktur, rajonirovanie territorii $\mathrm{i}$ akvatorii: VII vserossiyskaya nauchno-prakticheskaya konferentsiya (g.Vladivostok, aprel' 18-19). Vladivostok: Tihookeanskij institut geografii DVO RAN, 2019. P. 484491 (in Russian). 